
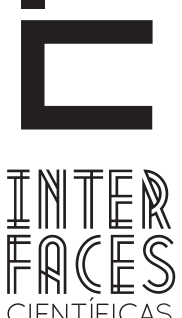

SAÚDE E AMBIENTE

\title{
BENEFÍCIOS DA AMAMENTAÇ̃̃O PARA SAÚDE MATERNA
}

\section{RESUMO}

A amamentação corresponde a uma das etapas mais importantes no processo reprodutivo da mulher, sua prática oferece benefícios tanto para mãe como para o recém-nascido. 0 objetivo desse trabalho é levantar dados e discutir informações atuais sobre o beneficio da amamentação para mulher. Trata-se de uma revisão da literatura realizada por meio de produções científicas, catalogadas a partir de buscas. Foram selecionados 18 artigos específicos publicados nos últimos 15 anos, 10 revisões de literatura e 8 estudos de casos sobre o tema. Com base nos resultados, pôde-se constatar que os benefícios da amamentação para saúde materna são pouco abordados. As benfeitorias que o aleitamento materno traz à criança são os tópicos mais relevantes ao abordar o tema amamentação. A mulher precisa ser informada da importância do o aleitamento materno para sua saúde e que o mesmo não beneficia exclusivamente a criança; o seu corpo também sofre influência ao realiza-lo.

\section{PALAVRAS- CHAVE}

Aleitamento Materno. Período Pós-parto. Bem Estar Materno. 


\section{ABSTRACT}

Breastfeeding represents one of the most important stages in a woman's reproductive process, his practice offers benefits for both mother and the newborn. The aim of this study is to collect data and discuss current information about the benefits of breastfeeding for women. This is a literature review performed by scientific productions, cataloged from searches. We selected 18 specific articles published in the last 15 years, 10 literature reviews and 8 case studies on the topic. Based on the results, it was noted that the benefits of breastfeeding for maternal health are poorly addressed. Improvements that breastfeeding brings the child are the most relevant topics when discussing breastfeeding. The woman must be informed of the importance of breastfeeding for your health and that it not only benefits the child, your body is also influenced to realize it.

\section{KEYWORDS}

Breastfeeding. Postpartum Period. Maternal Well-being.

\section{RESUMEN}

La lactancia materna corresponde a una de las etapas más importantes en el proceso reproductivo de la mujer, su práctica ofrece beneficios tanto para la madre como para el recién nacido. El objetivo de este estudio es recoger datos y analizar la información actual sobre los beneficios de la lactancia materna para las mujeres. Se trata de una revisión de la literatura realizada por las producciones científicas, catalogadas a partir de búsquedas. Se seleccionaron 18 artículos específicos publicados en los últimos 15 años, 10 revisiones bibliográficas y 8 estudios de casos sobre el tema. Con base en los resultados, se encontró que los beneficios de la lactancia para la salud materna son poco relatados. Los beneficios que la lactancia trae al niño son los temas más relevantes cuando se habla de la lactancia materna. La mujer debe ser informada de la importancia de la lactancia materna para su salud y que ésta no sólo beneficia al niño, su cuerpo también sufre influencias al realizarla.

\section{PALABRAS CLAVE}

La Lactancia Materna. Puerperio. El Bienestar Materno.

\section{INTRODUÇãO}

A amamentação corresponde a uma das etapas mais importantes no processo reprodutivo da mulher e sua prática oferece benefícios tanto para mãe como para o recém-nascido. Ao escolher o aleitamento materno exclusivo, a mãe provê alimento ao filho, promove a sua saúde e fortalece o contato afetivo, vínculo que se inicia na concepção, cresce durante a gestação e se fortalece com a amamentação (GALLO et al; 2008).

0 aleitamento materno é um processo fisiológico que traz inúmeras vantagens bio-psico-social para as puérperas. A produção do mesmo é estimulada após a saída da placenta, que faz decair os níveis de estrógeno/progesterona e aumentar os de prolactina, incitando a fabricação do leite pelas glândulas mamárias. (AZEVEDO et al, 2010)

Com o início da produção, o leite materno é distribuído em três tipos: colostro, leite de transição e leite maduro. 0 primeiro se caracteriza por ser rico em eletrólitos, proteínas, vitaminas, IgA e apresenta baixo teor de gordura e lactose, é secretado logo nos primeiros dias pós-parto. 0 leite de transição apresenta composição intermediária entre o colostro e o leite maduro, sua produção se dá de sete a quatorze dias 
após o parto. 0 último é produzido a partir da segunda quinzena pós-parto e é rico em gordura e lactose (ÁVILA, SALVAGNI, 2009).

No aspecto psicossocial, o processo de amamentação está relacionado ao binômio mãe e filho. De acordo com a Organização Mundial da Saúde (OMS) (2005), a prática do aleitamento deve ser exclusiva até os seis meses de vida do bebê. Segundo Castro et al (2008) até esta idade o leite materno é capaz de suprir as necessidades nutricionais do lactente, porém a partir desta idade a maioria das crianças atingem um nível de desenvolvimento geral e neurológico (mastigação, deglutição, digestão e excreção), tornando-se necessária a introdução de alimentos complementares para suprir suas necessidades nutricionais.

A amamentação é a melhor maneira de proporcionar o alimento para o Crescimento e desenvolvimento saudáveis dos recém-nascidos, além de ser parte integral do processo reprodutivo, com importantes implicações para a saúde materna (OMS; OPAS, 2005).

Nessa linha de intelecção, ilustrando o sobredito, vale observar as precisas ponderações de Giugliani (2000, p. 3) que colabora dizendo:

O aleitamento materno também contribui para a saúde da mulher, protegendo contra o câncer de mama e de ovário, ampliando o espaçamento entre os partos. A eficácia da lactação como anticoncepcional é de $98 \%$ nos primeiros 6 meses após o parto, desde que a amamentação seja exclusiva ou predominante e que a mãe se mantenha amenorreica. Outra vantagem para a saúde da mulher que amamenta é a involução uterina mais rápida, com consequente diminuição do sangramento pós-parto e de anemia.

Baseado nesses entendimentos, a amamentação deve ser iniciada de forma precoce, de preferência na primeira hora após o parto, sobre livre demanda e estimulando o contato pele a pele, que irá produzir melhor interação mãe-bebê, um eficaz controle da temperatura do recém-nascido, níveis mais altos de glicose e diminuição do choro. Pela sucção precoce do mamilo, espera-se diminuição do risco de hemorragia pós-parto, ao liberar ocitocina, e icterícia nos recém-nascido, ao aumentar a motilidade gastrintestinal (GIUGLIANI, 2000).

Segundo Gallo et al (2008) a amamentação resulta em benefícios para a saúde reprodutiva da mulher. Sua prática frequente e com mamadas duradouras contribui para preservar a saúde materna ao ampliar o espaçamento entre gestações e partos. Outras vantagens é proteger a mulher contra as neoplasias de mama e de ovários. A involução uterina mais rápida quando se amamenta, diminui os sangramentos pós-parto e favorece o retorno do peso pré-gestacional mais precocemente.

A amamentação protege contra infecções nas crianças diminuindo a mortalidade de lactentes (CARVALHO et al, 2006). Já as vantagens para a relação mãe e filho podem ser reportadas, tendo em vista que ao amamentar a mãe adquire o costume de oferecer aconchego à criança, promovendo o vínculo afetivo desejável na relação. Outros ganhos com a amamentação incluem a praticidade e a isenção de despesas com substitutos do leite materno.

Com o avanço da saúde e o conhecimento do papel da amamentação para a saúde da criança, sabe-se pouco a respeito dos benefícios do aleitamento materno para a mulher. Desse modo este estudo tem como objetivo levantar dados e discutir informações atuais sobre o beneficio da amamentação para mulher. 


\section{REVISÃO DE LITERATURA}

\subsection{BENEFÍCIOS PARA O RECÉM-NASCIDO}

Quando se discorre sobre os benefícios ofertados ao recém-nascido pelo ato de amamentar são observadas inúmeras vantagens dessa prática para a criança. A amamentação é a melhor forma de alimentação, por oferecer meios para um crescimento e desenvolvimento adequados. Permite o contato pele a pele entre a mãe e recém-nascido, promovendo uma troca de sentimento e de prazer ao ver suas necessidades sendo satisfeitas (MOURA et al,1999)

Relacionando-se com o aspecto psicológico, a amamentação favorece o desenvolvimento da personalidade da criança. Segundo Antunes et al (2006) as crianças que mamam no peito tendem a ser mais tranquilas e fáceis de socializar-se durante a infância. As experiências vivenciadas na primeira infância são extremamente importantes para determinar caráter do indivíduo quando adulto.

Antunes et al (2006) colabora dizendo:

A sucção, deglutição e respiração, funções primárias do bebê, são desenvolvidas através de uma correta forma de amamentação, devendo constituir um sistema equilibrado. Mamar não supre apenas a necessidade de alimentação, satisfazendo duas "fomes": a fome de se nutrir, de se sentir alimentado, como também a "fome" de sucção, que envolve componentes emocionais, psicológicos e orgânicos. Essas duas "fomes" devem estar em equilíbrio, caso contrário, a necessidade de sucção pode não ser alcançada, causando uma insatisfação emocional, e assim a criança buscará substituto como dedo, chupeta, ou objetos, adquirindo hábitos deletérios.

\subsection{BENEFÍCIOS MATERNOS}

Sabe-se que os benefícios da amamentação para saúde da mulher ainda não são muito informados du-
Segundo Carvalho et al (2006) a amamentação natural protege contra infecções comuns em crianças, como diarreias, doenças respiratórias agudas, otites médias e diversas infecções neonatais, diminuindo consideravelmente a mortalidade de lactentes. Além dos benefícios nutricionais, imunológicos, emocionais e socioeconômicos, o aleitamento materno, também tem efeitos positivos na saúde fonoaudiologia, uma vez que está relacionada ao crescimento e desenvolvimento craniofacial e motor-oral do recém-nascido.

Giugliani (2000, p. 3) contribui argumentado:

Além da proteção contra as doenças, o leite materno propicia uma nutrição de alta qualidade para a criança, promovendo o seu crescimento e desenvolvimento. É importante lembrar que as crianças amamentadas podem apresentar um crescimento diferente do das crianças alimentadas artificialmente.

Ela estimula um exercício físico contínuo que propicia o desenvolvimento da musculatura bucal, proporcionando o desenvolvimento facial. Isso direciona o crescimento de estruturas importantes, como seio maxilar para respiração e fonação. A amamentação proporciona à criança uma respiração correta. Além disso, associada ao mecanismo de sucção, desenvolve os órgãos fonoarticulatórios e a articulação dos sons das palavras, reduzindo a presença de maus hábitos orais e também de patologias fonoaudiologias (ANTUNES et al, 2006). 
tem para o bebê, embora saibamos que, para a mulher, a amamentação produz ganhos importantes, como o favorecimento do vinculo afetivo, satisfazendo e suprindo a separação abrupta ocorrida no momento do parto (ANTUNES et al, 2006)

Segundo Antunes et al (2006) no momento do parto já acontece a liberação de ocitocina, hormônio responsável pelas contrações uterinas. Sua ação maior acontece no ato da amamentação, relacionada à estimulação que a sucção causa sobre a glândula hipófise. A liberação desse hormônio reduz o tamanho do útero, que libera a placenta com isso diminuindo o sangramento pós-parto.

O efeito protetor da mama contra o câncer está relacionado às funções imunológicas, onde os macrófagos presentes no leite promovem a destruição das células neoplásicas (MOURA et al, 1999). O aleitamento materno pode ser responsável pela redução do câncer de mama, quanto mais demorado for o período de amamentação mais proteção se terá.

A gravidez, assim como a amamentação, está relacionada aos fatores de proteção do câncer de ovário.
Pelas interrupções de ovulação e proliferações celulares a amamentação inibe a ovulação tornando-se preventiva. Pode-se afirmar que o risco é menor em mulheres que amamentam (REA, 2004).

No período da gravidez a mulher acumula de 100 a 150 calorias por dia, podendo terminar a gestação com sobrepeso, sendo necessário, para voltar ao peso pré-gravidez, esperar algum tempo. No período de lactação, a mulher não consome a necessária quantidade de calorias para produzir o leite que o bebê ingere, sendo necessário amamentar, assim o organismo retirará a quantidade necessária de calorias acumuladas na reserva para produção do leite. Quando a amamentação é exclusiva todas as calorias consumidas pelo bebê ao amamentar são de origem materna, assim a quantidade retirada da mãe será maior (REA, 2006).

Ao interromper o ato de amamentar precocemente as calorias que seriam gastas ficam armazenadas, conservando o peso ganho na gestação por mais tempo. Consequentemente demorando se mais para voltar ao peso pré-gestacional (REA, 2006).

para a saúde materna. A partir desse levantamento, foram selecionados 18 artigos específicos sobre 0 tema publicados nos últimos 15 anos. Foram incluídos 10 revisões de literatura e 8 estudos de casos. Apenas os estudos de casos foram apresentados de forma descritiva, enquanto os de revisão foram utilizados como suporte para a discussão.

Foram selecionados estudos, preferencialmente ensaios clínicos e revisões de literatura que demonstram a importância do beneficio da amamentação 


\section{RESULTADO}

Os benefícios para a saúde materna constituíram o foco principal deste estudo. Ao termino da busca, foram encontrados 8 trabalhos com os descritores mencionados. Levando em consideração os critérios de seleção desta revisão, foram incluídos 3 artigos onde falava diretamente dos benefícios da amamentação pra saúde materna e os outros 6 mencionavam de forma geral a importância da amamentação para a mulher e o vinculo afetivo que ela proporciona. Todos os artigos são de revistas nacionais.

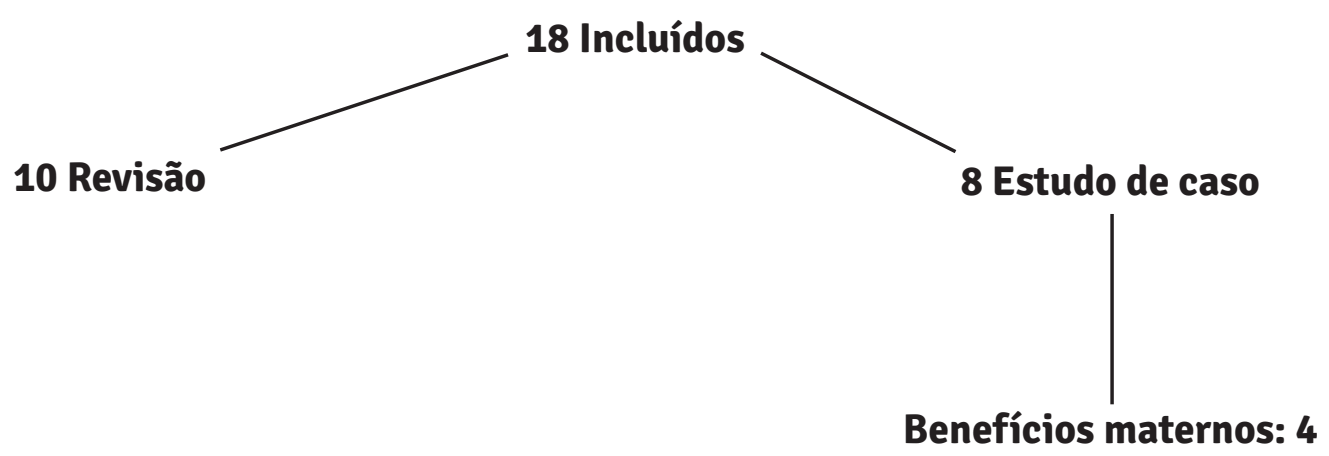

\section{Benefícios da criança: 5}

\section{DISCUSSÃO}

Os artigos analisados abordam de forma ampla as vantagens que o aleitamento proporciona à saúde de um modo geral. Partindo-se dos resultados descritos nesses estudos conclui-se que tal ato não beneficia somente a mãe ou a criança, mas sim o binômio de forma única e positiva.

De acordo com o estudo de Azevedo et al (2010), de natureza descritiva com abordagem quantitativa; realizado no Alojamento Conjunto (AC) da Maternidade Escola Assis Chateaubriand (MEAC) em Fortaleza-CE; com uma amostra de 252 mulheres e com objetivo de identificar o conhecimento das primíparas a respeito dos benefícios do aleitamento materno para a mãe e o recém-nascido; observou-se que a saúde e o valor nutricional foram os benefícios para o bebê mais ci- tados $(48,0 \%$ e $14,7 \%)$ e, que um percentual elevado das mulheres $(69,8 \%)$ desconhecia as vantagens que a amamentação poderia proporcioná-la.

Sabe-se que conhecimentos corretos sobre aspectos relevantes do aleitamento materno contribuem para o sucesso desse processo, porém não determinam que a amamentação seja realizada com eficácia. Logo, aponta-se a necessidade de programas educativos consistentes e uma assistência integral a mulher, que contemple o ciclo gravídico-puerperal, além de um cuidado global à saúde da criança.

Já no estudo de Coutinho (2009), com o objetivo de conhecer a importância referida pela mãe da amamentação na relação com seu filho, como também de 
identificar as vantagens da amamentação referidas pela mãe e quais as razões para o abandono do aleitamento materno, verificou-se que as mesmas iniciam a amamentação essencialmente devido às vantagens que conhecem sobre o aleitamento materno.

Outra questão abordada foi se durante a gravidez foi explicada as vantagens da amamentação tendo como resposta que 38 (95\%) das mulheres foram explicadas das vantagens do aleitamento materno e 2 (5\%) não foram explicadas das suas vantagens.

Quando se pergunta quais vantagens elas identificam com a amamentação tiveram 76 respostas das quais 9 eram diferentes. As respostas das mulheres foram: propriedades protetoras contra doenças, saudável, alimento completo, melhora a relação mãelfilho, pratico, econômico, previne o câncer de mama, facilita a involução uterina e recuperação pós-parto mais rápida.

Verifica que $28(70 \%)$ das mulheres inqueridas identificaram como vantagem o fato de o leite apresentar propriedades protetoras contra doenças, 20 (50\%) o fato do leite materno melhorar a relação mãel filho, 17 (42,5\%) considera que o leite materno é saudável, $3(7,5 \%)$ responderam igualmente ser um alimento saudável, econômico e, apenas com 1 (2,5\%) resposta, respectivamente as vantagens: previne 0 câncer de mama, facilita a involução uterina e recuperação pós-parto mais rápida.

Para responder esses objetivos foi aplicado um questionário a uma amostra de 40 mães inscritas num Centro de Saúde da Beira Litoral. Através dos resultados.

Em um estudo qualitativo de Gallo et al (2008), fez-se uma entrevista semi-estruturada sobre motivação para amamentar, com 164 gestantes assistidas no pré-natal em dois Centros de Saúde na região central da cidade de São Paulo. O resultado encontrado foi que as principais categorias identificadas estavam relacionadas à saúde da criança, da mulher e aos benefícios da prática de amamentar e do leite materno.
A maioria das mulheres $(98,8 \%)$ foi favorável à amamentação. Benefícios à saúde da criança foi o motivo mais frequente $(73,8 \%)$. Concluímos que a motivação ao aleitamento materno foi centrada nos benefícios à saúde da criança. A amamentação é valorizada independentemente da vontade materna.

"Porque faz bem para o nenê, para os dois e emagrece".

Essa é uma das falas mencionadas no artigo e justificativa o que foi observado quando se refere à aprendizagem sobre amamentação, ou seja, quando relacionada à saúde materna, ocorre com o objetivo de assegurar boas condições ao aleitamento materno e não no sentido de conscientizar a mulher para o fato do que acontece no seu corpo. 0 foco do atendimento nesse período em relação à saúde volta-se para a criança.

As vantagens à saúde da mulher que amamenta foram muito pouco citadas. Mas ainda se fala em uma motivação de enaltecer essa pratica com vantagens decorrentes da amamentação para a própria saúde das mulheres.

No estudo de Araújo, et al (2008) identificou-se os motivos que levaram as mulheres ao desmame precoce e analisou o conhecimento das mães sobre a amamentação. Foi uma pesquisa de abordagem qualitativa, o universo empírico considerado foi de mães que desmamaram seus filhos precocemente (antes dos seis meses de idade), realizados em Teresina- PI, com 11 mães na faixa etária de 18 a 43 anos.

Os relatos foram coletados a partir de uma entrevista semi-estruturada, que possibilitou o surgimento de duas categorias: compreensão sobre amamentação e fatores que levaram ao desmame precoce. Ao analisar obteve que os fatores que motivaram ao desmame precoce foram enfermidades da mãe, que impediam o aleitamento, medicamentos utilizados por elas e substituição do leite materno por outro alimento. 
Ao verificar o conhecimento de puérperas adolescentes e adultas sobre amamentação Carvalho, et al (2006) fez um estudo transversal realizado por meio de questionário aplicado a mães no Hospital Maternidade de Santa Izabel, Bauru (SP). Estudou puérperas até 29 dias pós-parto, que responderam questões sobre aleitamento materno, aspectos demográficos e orientações recebidas sobre a amamentação no que se refere às suas vantagens e dificuldades. Incluíram as adolescentes primigestas no Grupo 1, adultas primigestas no Grupo 2 e adultas multíparas no Grupo 3. Onde se estudaram 61 puérperas, 18 (29,5\%) eram do Grupo 1, 23 (37,7\%) do Grupo 2 e 20 (32,8\%) do Grupo 3.

Todas as mães realizaram pré-natal, mas apenas $10(16,4 \%)$ receberam orientações sobre o aleitamento e $12(19,7 \%)$ foram orientadas sobre o preparo das mamas antes do parto, não havendo diferença entre os três grupos em relação à resposta a essas duas questões. Ao redor de $80 \%$ das puérperas ignoravam a importância da amamentação no desenvolvimento da fala, sendo o desconhecimento maior no grupo das adolescentes. Ao redor de $50 \%$ das mães adotavam a posição deitada durante a amamentação, sem diferença entre os grupos. 0 grau de conhecimento sobre a amamentação foi baixo nos três grupos de mães.

Em um estudo qualitativo com fatores relacionados ao desmame precoce Albuquerque, et al (2009) coletou dados em uma entrevista-semiestruturada com 20 mães de menores de seis meses em desmame precoce. Foram encontrados os seguintes resultados que apontaram alguns fatores que interferem no aleitamento materno exclusivo: a má interpretação do choro do lactente com relação à fome; insuficiência do leite materno; a necessidade do trabalho para ajuda na despesa da casa; dificuldade relacionada com as mamas e recusa do seio por parte do lactente.

Apesar do conhecimento materno sobre os benefícios do leite materno e da importância de amamentá-los exclusivamente durante os seis meses, elas vi- venciam dificuldades, onde se percebe contradições favoráveis e desfavoráveis, duvidas e dificuldade á pratica do aleitamento materno.

No estudo de Nakano (2003) buscando compreender o significado atribuído, por um grupo de mulheres da cidade de Ribeirão Preto, São Paulo, sobre as vivências da amamentação no que se refere às sensações e manifestações em seus corpos, bem como as percebidas nos corpos de seus filhos. Entendeu esse fenômeno integrado a sistemas de valores da maternidade e do corpo.

Constitui-se de uma pesquisa qualitativa. Participaram 20 primíparas, que procuraram as unidades básicas de saúde por razão adversa à amamentação. A análise das entrevistas e observações baseou-se na técnica de análise de conteúdo. Para essas mulheres, amamentar é ser uma boa mãe e dar o melhor para o filho. Na prática da amamentação, entre limites e possibilidades, dimensionam o que consideram "problema”, baseando-se nas manifestações percebidas em seus corpos e, prioritariamente, nos corpos de seus filhos. Suas preocupações estão fundadas nos prejuízos e perigos a que expõem o filho. Tais vivências se processam nos limites de ser: o corpo para o filho e o corpo para si, o que confere um vivido conflito entre maternidade e individualidade.

Shimoda e Silva (2010), em estudo, entrevistaram 238 mulheres sobre as necessidades de saúde no processo da amamentação. Organizaram os dados segundo proposta do Discurso do Sujeito Coletivo. Utilizando taxonomia de Matsumoto, encontraram: necessidades de boas condições de vida (ter boa alimentação; trabalhar/estudar; ter tempo para si; sono e repouso adequados; boa saúde mental; boas condições para amamentar seu filho); Necessidade de ter acesso a todas as tecnologias de saúde que contribuam para melhorar e prolongar a vida (lidar com intercorrências da amamentação, ter acesso aos serviços de saúde); necessidade de ter vínculo com um profissional/equipe de saúde; necessidade de autonomia 
e autocuidado na escolha do modo de "andar a vida" (ter orientação quanto à amamentação; receber apoio do profissional; sentir-se segura para amamentar).

Esses resultados apontaram a importância de o sistema de saúde incluir a família da nutriz no processo de amamentação e, também, levar o serviço de saúde para a realidade na qual vive a mulher, como forma de facilitar o acesso à informação e ao atendimento de saúde.

\section{CONCLUSÃO}

Apesar da necessidade de mais pesquisas científicas sobre o tema abordado, os estudos realizados e incluídos nesta revisão indicam que os benefícios da amamentação para saúde materna são de grande importância. Quando a mulher conhece as vantagens que a amamentação a favorece isso promove o aumento do tempo do aleitamento materno para a criança, melhorando assim a relação afetiva mãelfilho.

Com base nos estudos abordados pôde-se perceber uma falha dos profissionais de saúde em não informar de forma direta às vantagens que o corpo da mulher sofre quando ela escolhe o aleitamento exclusivo. Toda ação esta voltada para vantagens ligadas com benefícios para criança deixando de lado que a mãe, também, tem que se sentir estimulada para realizar essa prática.
Com base nos resultados deste estudo, pôde-se constatar que os benefícios da amamentação para saúde materna são pouco abordados. Os fatores que tem maior relevância para amamentação estão direcionados para os benefícios que o aleitamento materno tem para a criança. Com isso a mulher precisa ser informada da importância do aleitamento para sua saúde e saber que não só a criança que se beneficia com essa prática, o seu corpo também sofre influência ao realizá-la.

Constatou-se que realmente não é ampla a literatura e nem se encontram pesquisas suficientes que abordem o tema de forma completa. Percebe-se a necessidade de explorar e divulgar os benefícios da amamentação para a saúde da mulher.

Estudos de impacto sobre como programar essa prática são ainda escassos. Uma das razões pode ser a dificuldade de não se conseguir isolar e estudar um único fato (ou intervenção), devido à inter-relação de fatores ambientais e socioculturais que atuam na prática de amamentar, mesclando políticas públicas, benefícios, rotinas, ações de profissionais. De toda maneira, permanece o desafio aos acadêmicos e profissionais de saúde pública, já que intervenções nesta área devem observar prioridades de custo e efetividade.

\section{REFERÊNCIAS}

ALBUQUERQUE, C.M. et al. Fatores que interferem no Aleitamento Materno. Rev. Rene. Fortaleza, v. 10, n. 3, p. 61-67, jul./set.2009. Disponível em:<http://www.revistarene.ufc.br/10.3/html/6.htm>. Acesso em: 05 fev. 2013. 
ANTUNES, L. S. et al. Amamentação natural como fonte de prevenção em saúde. Ciência \& Saúde Coletiva: 103-109, 2008 Disponível em: <http://www.scielosp.org/pdf/csc/v13n1/14.pdf>. Acesso em: 15 jan. 2013.

ÁVILA , I; SALVAGNI, E.P. Aleitamento Materno. Universidade Federal do Rio Grande do Sul, Faculdade de Medicina. Promoção e proteção da saúde da criança e do Adolescente. 2009. P 15- 18. Disponível em: <http://www. lume.ufrgs.br/bitstream/handle/10183/26647/000731106.pdf?sequence=1>iro>. Acesso em: 15 jan. 2013.

ARAUJO, O.D. et al. Aleitamento materno fatores que levam ao desmame precoce. Revista Brasileira de Enfermagem. Brasília. 2008; 61(4):488-92. Disponível em: <http://www.scielo.br/pdf/reben/v61n4/15.pdf>. Acesso em: 05 fev. 2013.

AZEVEDO, D.S. et al. Conhecimento de Primíparas Sobre os Benefícios do Aleitamento materno. Rev. Rene. Fortaleza, v. 11, n. 2, p. 53-62, abr./jun.2010. Disponível em: <http://www.revistarene.ufc.br/vol11n2_html_ site/a06v11n2.htm>. Acesso em: 22 jan. 2013.

CARVALHO, A.P. et al. Conhecimento sobre amamentação: comparação entre puérperas adolescentes e adultas. Rev Paul Pediatria 2006; 24(2): 121-126. Disponível em: < http://www.spsp.org.br/Revista_RPP/24-15. pdf>. Acesso em: 22 jan. 2013.

CASTRO, S.V. et al. Aspectos do Aleitamento Materno. Revista Digital de Nutrição - Ipatinga: Unileste-MG, V. 2 - N. 2 - Fev./Jul. 2008. Disponível em:<http://www.unilestemg.br/nutrirgerais/downloads/artigos/aspectos_aleitamento_materno.pdf $>$. Acesso em: 22 jan. 2013.

COUTINHO, B.S.T. A importância da amamentação na relação mãe-filho. Universidade Fernando Pessoa, Ponte de Lima, 2009. Disponível em: <http://bdigital.ufp.pt/bitstream/10284/1161/2/monografia.pdf >. Acesso em: 13 fev. 2013.

GALLO, P.R; et al. Motivação de gestantes para o aleitamento materno. Revista de Nutrição, Campinas. 2008. Disponível em: <http://www.scielo.br/pdf/rn/v21n5/a02v21n5.pdf>. Acesso em: 15 jan. 2013.

GIUGLIANI, E. R. J. $O$ aleitamento materno na prática clínica. Jornal de Pediatria - Vol. 76, Supl.3, 2000. Porto Alegre. Disponível em: <http://www.jped.com.br/conteudo/00-76-s238/port.pdf >. Acesso em: 13 de fevereiro de 2013.

ICHISATO, S. M. T.; SHIMA, A. K. K. Aleitamento Materno e as Crenças Alimentares. Rev. Latino-Americana de Enfermagem. 2001. Disponível em: <http://www.scielo.br/pdf/rlae/v9n5/7801.pdf >. Acesso em: 22 jan.2013.

ICHISATO, S. M. T.; SHIMA, A. K. K. Revisando o desmame precoce através de recortes da história. Rev. Latino-Americana de Enfermagem. 2002. Disponível em: <http://www.scielo.br/pdf/rlae/v10n4/13371.pdf> Acesso em: 22 jan. 2013.

MOURA, A. C. et al. AMAMENTAÇÃO COM ENFOQUE NA SAÚDE DA MULHER. Universidade Vale do Rio Doce - UNIVALE. 1999. Disponível em: <http://srvwebbib.univale.br/pergamum/tcc/Amamentacaocomenfoquenasaudedamulher.pdf $>$. Acesso em: 22 jan. 2013. 
NAKANO, A.N. S. As vivências da amamentação para um grupo de mulheres: nos limites de ser "o corpo para o filho" e de ser "o corpo para si”. Cad. Saúde Pública. Rio de Janeiro. 2003. Disponível em: <http://www.scielo. br/pdf/csp/v19s2/a17v19s2.pdf>. Acesso em: 13 fev. 2013.

Organização Mundial da Saúde ( OMS). Estratégia Global para a Alimentação de Lactentes e Crianças de Primeira Infância. UNICEF; IBFAN Brasil. Setembro de 2005. Disponível em: <http://www.ibfan.org.br/documentos/ibfan/doc-286.pdf>. Acesso em: 15 jan. 2013.

REA, M. F. Os benefícios da amamentação para a saúde da mulher. Jornal de Pediatria - vol. 80, n. 5, 2004. Disponível em: <http://www.scielo.br/pdf/jped/v80n5s0/v80n5s0a05>. Acesso em: 15 jan.2013.

REA, M.F; TOMA, T.S. Benefícios da amamentação para a saúde da mulher e da criança: um ensaio sobre as evidências. Cad. Saúde Pública. Rio de Janeiro, 2008. Disponível em: <http://www.scielo.br/pdf/csp/v24s2/09. pdf >. Acesso em: 15 jan. 2013.

SHIMODA, G.T; SILVA, I.A. Necessidades de saúde de mulheres em processo de amamentação. Ver. Bras. Enferm. Brasília. 2010. Disponível em: <http://www.scielo.br/scielo.php?script=sci_arttextapid $=$ S0034-71672010000100010>. Acesso em: 13 fev. 2013. 